\title{
Fiftieth anniversary of the Dunn School of Pathology
}
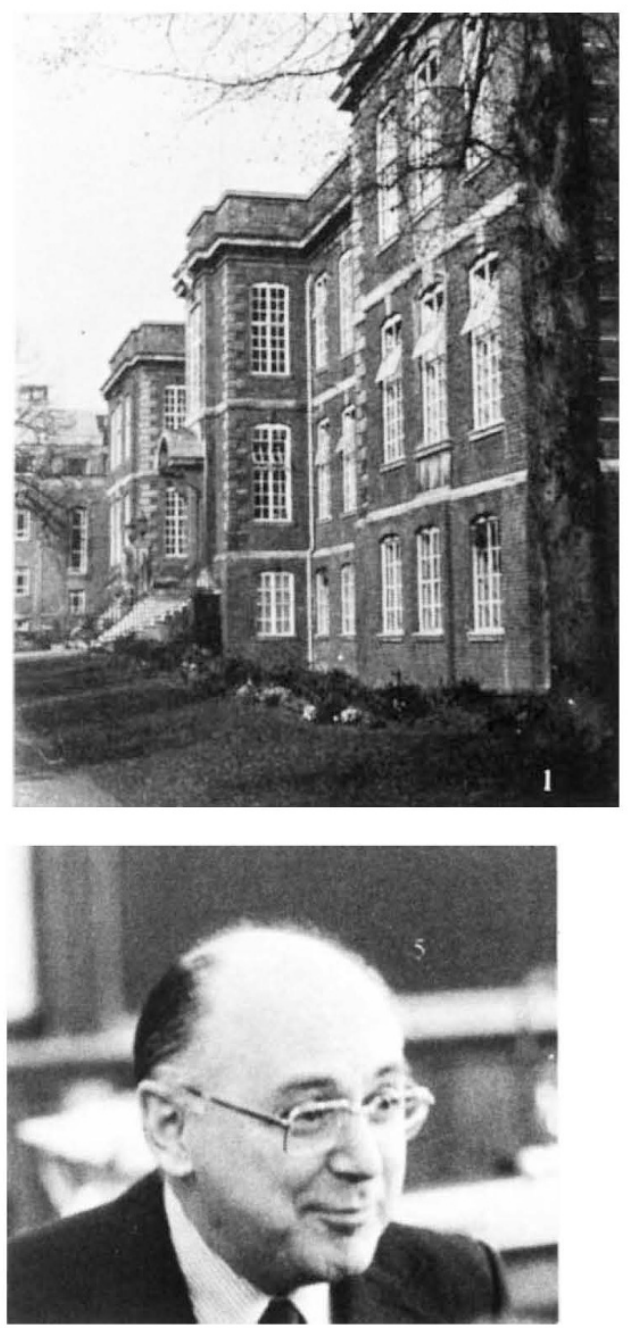

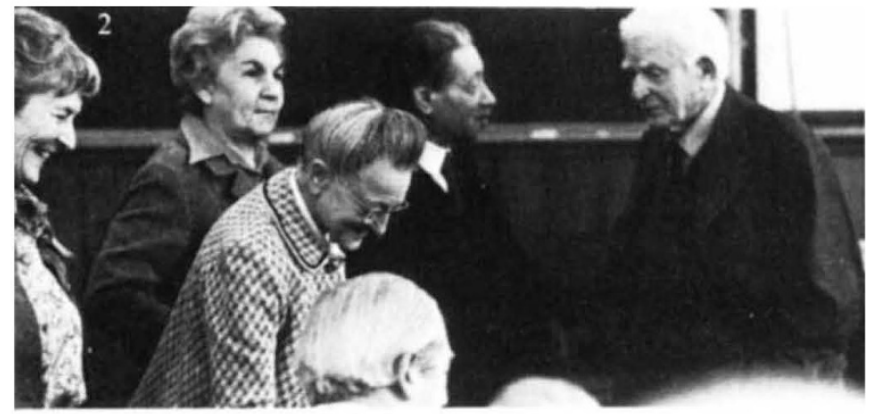

1 The Sir William Dunn School of Pathology

2 Dr Jean Medawar, Dr Anne Beloff-Chain, Lady Florey, Sir Peter Medawar, Sir Ernst Chain, Professor A. D. Gardner

3 Dr George Mackaness

4 Professor Dorothy Hodgkin, Professor D. Whitteridge 5 Professor Henry Harris
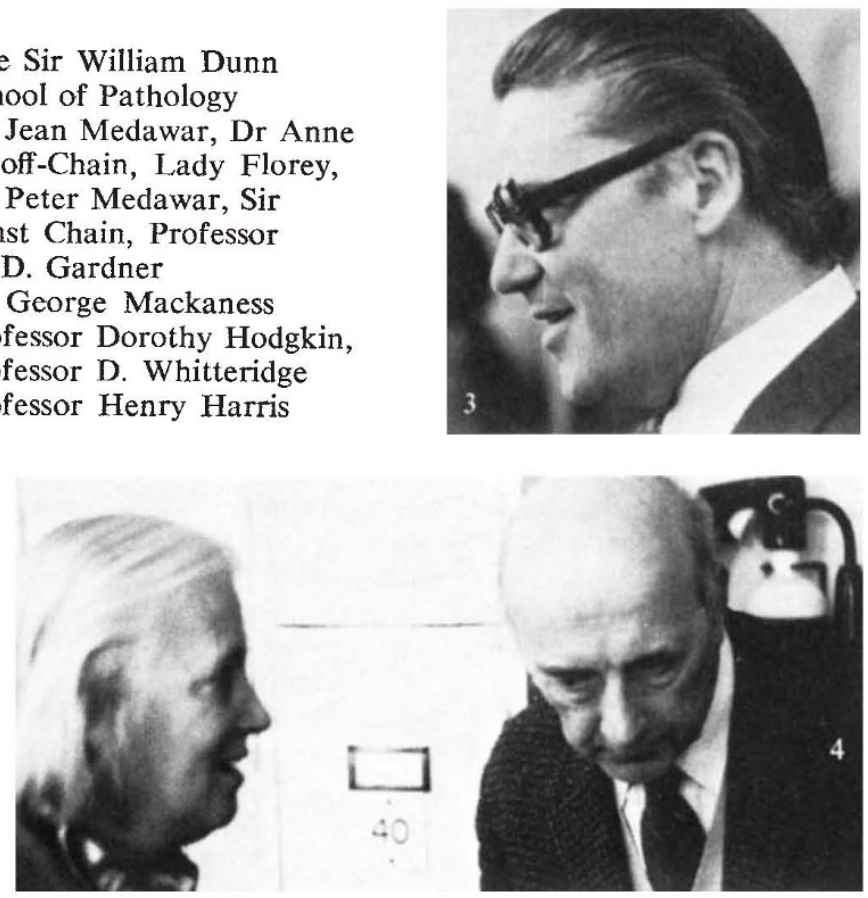

hard-wearing female technicians. In 1952 when Henry Harris arrived from Sydney, Florey's direct interests in antibiotics were being wound up in J. L. Gowans' DPhil thesis. Thereafter antibiotic research was carried out under E. P. Abraham who told the story of cephalosporins from their bizarre origins in a Sardinian sewage outlet to the present day.

Florey's interests, ruled as ever according to Professor Harris by the illnesses with which he or members of his family were afflicted, turned to atherosclerosis, gastric secretion and inflammation. A three-pronged attack on inflammation was mounted by Florey through George Mackaness, Gowans and Harris who were to investigate the roles of the macrophage, the lymphocyte and the polymorph, respectively. Only Harris gave up. His decision that the polymorph had been good for a DPhil but would not do for a career brought out the fiercest in Florey. Harris was threatened with deportation to Australia, and communication between the two became confined to letters. Fortunately Harris's colleagues, particularly Abraham, rallied round and persuaded Florey to back down. Henry Harris survived to take over Florey's chair in 1963. We look forward to the 75th anniversary of the Sir William Dunn School of Pathology when tales of Henry Harris can best be told, perhaps under the shade of the ginko tree ceremonially planted by his wife on this occasion.

Peter Newmark 